\title{
ENSINO BILINGUE EM MOÇAMBIQUE: INTRODUÇÃO E PERCURSOS
}

\author{
BILINGUAL EDUCATION IN MOZAMBIQUE: INTRODUCTION AND PATHWAYS
}

\begin{abstract}
Ezra Alberto Chambal Nhampoca
Doutoranda em Linguística pela Universidade Federal de Santa Catarina

Docente na Universidade Eduardo Mondlane, Moçambique

Faculdade de Letras e Ciências Sociais Departamento de Línguas - Secção de Línguas Bantu ch_ezra@yahoo.com.br
\end{abstract}

Resumo: O presente artigo objetiva oferecer uma visão geral do processo de introdução do Ensino Bilíngue (EB) em Moçambique. Aborda os percursos traçados nesse processo, e alguns dos problemas e desafios daí decorrentes, sobretudo o convívio conflituoso entre as Línguas Bantu e o Português, tendo em conta o contexto sociocultural do país, caracterizado por uma diversidade linguística, étnica e cultural. $\mathrm{O}$ trabalho apresenta também o modelo transicional, que foi adotado por Moçambique no processo de introdução do EB, além de algumas opiniões avaliativas sobre esse modelo, assim como sobre o EB de modo geral. Para o estudo, realizou-se uma pesquisa bibliográfica em materiais anteriores acerca do assunto, duas conversas com dois pesquisadores da área, e, por fim, foi considerada a experiência da própria autora como falante e pesquisadora de uma Língua Bantu (LB). No que respeita ao referencial teórico, o trabalho baseou-se nas perspectivas de Patel (2006), Chambo (2013), Severo (2014), Sitoe (2014), entre outros. Verificouse que, desde a introdução do EB, acadêmicos e sociedade, embora reconheçam que há ainda problemas por solucionar, avaliam-no positivamente e acreditam ser um projeto sério e capaz de resolver os problemas pedagógicos existentes no sistema de educação de Moçambique (SITOE, 2014). Observou-se também que o Ensino Bilíngue em Moçambique trouxe mais inclusão tanto das línguas como dos sujeitos, seus falantes, pois usar as línguas dos indivíduos na sua educação e na educação de seus filhos permite que esses sujeitos usem suas línguas em outros meios no seu dia a dia.

Palavras-chave: Ensino Bilingue; Línguas Bantu; Moçambique; Modelo transicional; Português. 
Abstract: This article aims to present an overview of the process of implementation of Bilingual Education (BE) in Mozambique. It discusses the paths outlined in this process and some of the problems and challenges involved in it, especially the conflictual interaction between Bantu and Portuguese Languages, considering the socio-cultural context of the country, which is characterized by a linguistic, ethnic and cultural diversity. This work also presents the transitional model, adopted in the process of implementation of $\mathrm{BE}$ in Mozambique. It presents some evaluative views about the transitional model as well as about the bilingual education in general. For this study, a literature review was drawn based on previous materials on the subject. Moreover, two interviews with two researchers in the field were conducted, and finally it was also considered the experience of the author of this paper as a Bantu Language speaker and as a Bantu language student. Regarding the theoretical framework, the prospects of Patel (2006), Chambo (2013), Severo (2014), Sitoe (2014), among others, were considered. In conclusion, it was found that scholars and society evaluated positively the implementation of BE, even acknowledging that there still are problems to be solved. They also believed that it is a serious project and an useful way to solve the pedagogical problems in Mozambique educational system. Besides that, it was noted that the bilingual education in Mozambique has increased the inclusion of both languages and speakers, whereas using the languages of individuals in their formal education allows these individuals to use their languages in all instances of their day-to-day life.

Keywords: Bilingual Education; Bantu languages; Mozambique; Transitional model; Portuguese.

\section{Introdução}

Moçambique é um país africano localizado na zona austral do continente. Como sucede com a maioria dos países africanos, é multilíngue e multicultural. Esses aspectos proporcionam ao país uma diversidade cultural e linguística: "A diversidade linguística de Moçambique é uma das suas principais características culturais” (INE, 1997 apud PATEL, 2006). O acervo linguístico de Moçambique é formado por línguas de origem africana (Bantu), europeia, asiática e línguas do Médio Oriente, sendo as línguas de origem bantu as mais faladas, como sustenta Patel (2006), ao referir que a maioria dos moçambicanos é bilíngue no contexto de Línguas Bantu (LB) moçambicanas e, por vezes, 
até trilíngue, sobretudo dentro de um mesmo grupo linguístico ${ }^{1}$. Apesar dessa permeabilidade de uso das LB, o Português é até o momento atual a única língua oficial do país, adotado como língua de unidade dos moçambicanos durante a preparação e o decurso da luta armada de libertação nacional (1962-1974) e posteriormente como língua oficial depois da Independência em 1975. Nesse contexto, o Português foi, durante muito tempo, a única língua de ensino num país em que a grande maioria tinha uma LB como materna, o que começou a se refletir no ensino, com recorrentes altas taxas de reprovação.

Perante esse quadro e também considerando as pressões da sociedade, o governo introduziu o EB a partir de 2002. É nessa discussão que o presente artigo se insere, com o objetivo de apresentar um panorama sobre o percurso do EB em Moçambique, focalizando, para tal, os contextos sócio-histórico e sociolinguístico de Moçambique; as ações visando políticas linguísticas e os impasses próprios de um país recém-independente multicultural e multilíngue; o EB em si e as motivações que ditaram sua introdução, bem como o contexto sociopolítico em que foi concebido, aprovado e implementado; o tipo de modelo adotado (o modelo transicional); e, por fim, algumas opiniões sobre o modelo transicional, assim como a avaliação que hoje se faz sobre o EB no geral e em particular sobre o modelo adotado, pois passados esses anos, desde a sua introdução, sente-se que acadêmicos e sociedade, embora reconheçam que há ainda vários problemas por solucionar, avaliam positivamente o EB. Dentre vários, Sitoe (2014, p. 66-67) é um exemplo. $\mathrm{O}$ autor afirma que “[a] educação bilingue é um projeto sério e único capaz de resolver os problemas pedagógicos de que hoje o sistema de educação em Moçambique enferma”. Em termos metodológicos, o trabalho baseou-se na pesquisa bibliográfica, assim como se recolheu depoimentos de dois professores que trabalham com questões linguísticas em Moçambique, e usou-se também a experiência da própria autora como falante nativa de uma LB e como pesquisadora já há cerca de uma década na área de Linguística Bantu, onde essa questão de EB é constantemente discutida.

Este trabalho organiza-se em três seções, a saber: na Seção 2, explana-se sobre a localização geográfica de Moçambique e sua situação sociolinguística; na Seção 3, o artigo aborda alguns eventos que atecederam a introdução do EB em Moçambique, bem como alguns problemas relacionados com o processo; na terceira seção, apresenta-se de

\footnotetext{
${ }^{1}$ Grupo ou subgrupo de línguas muito próximas que, em geral, são mutuamente inteligíveis.
} 
forma breve alguns pontos sobre a avaliação geral do EB, assim como algumas ações visando o uso e a valorização das LB nos últimos anos. Na sequência, apresentam-se as considerações finais.

\section{Localização geográfica, línguas e contexto sociolinguístico de Moçambique}

Moçambique é um país que se localiza na costa oriental da África Austral. É banhado pelo Oceano Índico, a leste; a Norte, faz fronteira com Tanzânia; a Noroeste, com Malawi e Zâmbia; a Oeste, com Zimbabwe; e, a Sudoeste, com Swazilândia e África do Sul. A capital e maior cidade do país é Maputo (MOÇAMBIQUE, 2016), possui 11 províncias e 128 distritos (PATEL e CAVALCANTI, 2013). O último censo populacional oficial foi realizado em 2007 e se apurou que Moçambique a essa data possuía uma população de 20.632.434 de habitantes (6.269.621 na zona urbana e 14.362.813 na zona rural) (NGUNGA e FAQUIR, 2011 apud INE, 2010). Projeções posteriores à data do último censo mostram 22.000.000 de habitantes em 2014 (TIMBANE, 2014) e 26.423.623 de habitantes em 2016 (INE, 2016).

No que respeita ao número de línguas de origem bantu faladas em Moçambique, não há consenso. Por um lado, há a literatura que considera cerca de 40 LB (ver mapa 1). E por outro, há a que considera 20 línguas, como é o caso da Secção de Línguas Bantu (SLB) da Universidade Eduardo Mondlane (2014) que afirma, no seu folheto de apresentação, que "Moçambique possui cerca de 20 línguas bantu, faladas por $80 \%$ da população quer como língua materna quer como língua segunda”. Para efeitos deste artigo, optou-se pela perspectiva da SLB, por se ter verificado que a maior parte das 40 línguas apontadas serem, na maioria dos casos, variedades de uma mesma língua. Das 20 línguas mencionadas pela SLB, 19 são atualmente ensinadas pela mesma, no curso de Licenciatura em Ensino de Línguas Bantu. São elas: Cibalke, Cicopi, Cindau, Cimanyika, Cinyanja, Cinyungwe, Cisena, Citshwa, Ciute, Ciyaawo, Echuwabo, Ekoti, Elomwe, Emakhuwa, Gitonga, Kimwani, Shimakonde, XiChangana e Xirhonga (UNIVERSIDADE EDUARDO MONDLANE, 2014). A maior parte dessas 19 línguas está presente no âmbito do EB, introduzido em 2002/2003 no país. Para além do Português e das LB moçambicanas, há outras línguas faladas no território, como as de origem europeia (Francês, Espanhol, Inglês e Alemão), de origem asiática e línguas do Médio Oriente (Mandarim, Urdu, Gujurati, Indi e Memane), e de origem africana (Swahili, Zulu). 
Figura 1. Mapa linguístico de Moçambique

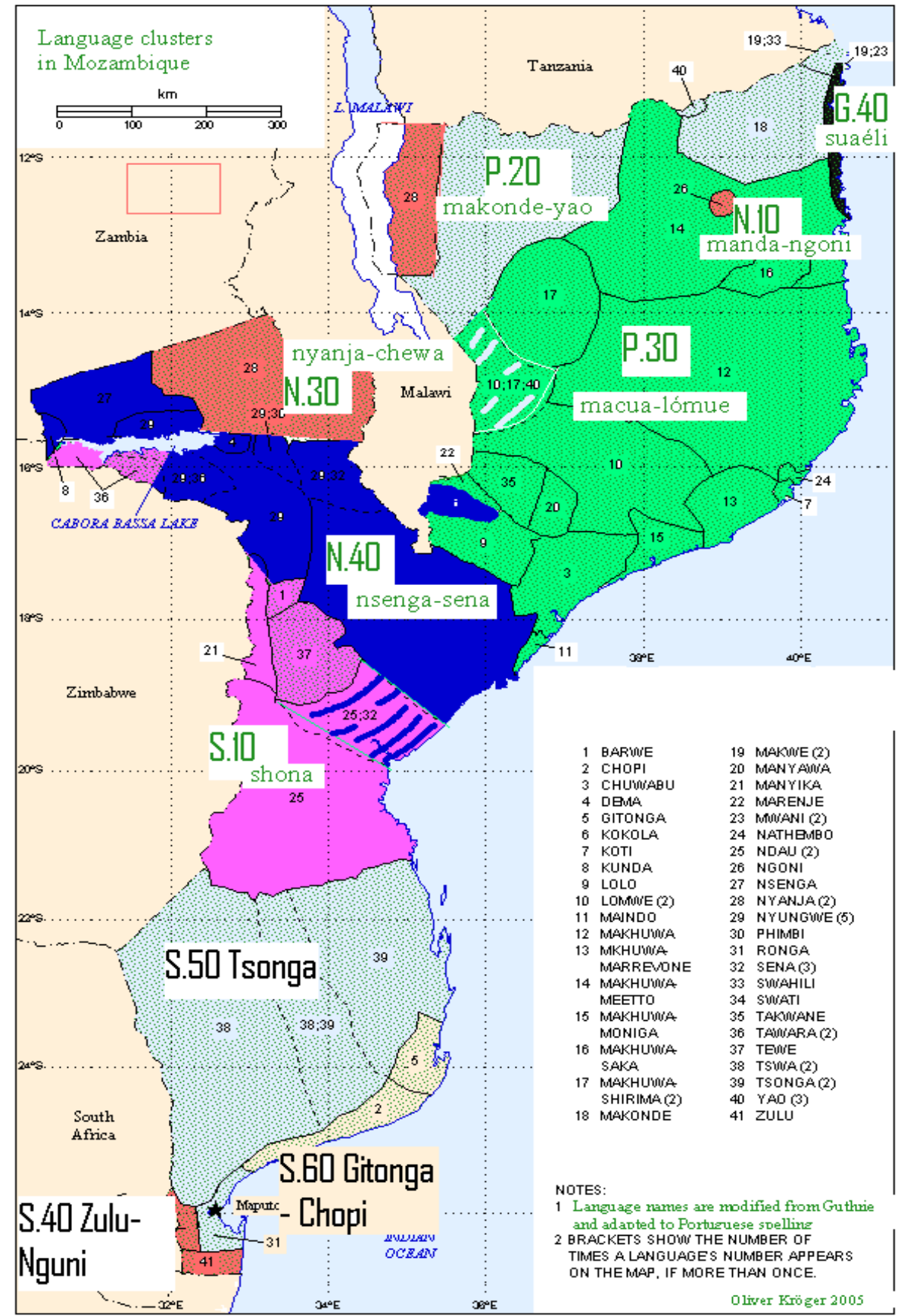

Fonte: Secção de Línguas Bantu - Universidade Eduardo Mondlane (2014). 
Moçambique, como a maioria dos países da região, é multicultural e multilíngue, sendo que predomina a população pertencente aos povos Bantu. A maior parte dos moçambicanos "habita nas zonas rurais e preserva a sua cultura, hábitos, costumes e as suas línguas locais, sempre respeitando a tradição oral. Aliás, este é um fenômeno característico dos povos Bantu” (TIMBANE, 2014, p. 1). Assim, a diversidade cultural do país também se reflete no fator linguístico - aliás, a diversidade linguística de Moçambique é uma das suas principais características culturais.

Apesar da notável preferência dos moçambicanos pelo uso das LB em relação ao Português, essa língua permaneceu e permanece como a única oficial de Moçambique e as LB são consideradas línguas patrimoniais, como se pode conferir a seguir, nos extratos da Constituição da República de Moçambique (CRM), designada "Lei-Mãe":

Artigo 9 (Línguas nacionais) - O Estado valoriza as línguas Nacionais como património cultural e educacional e promove o seu desenvolvimento e utilização crescente como línguas veiculares da nossa identidade. Artigo 10 (Língua oficial) - Na República de Moçambique a língua portuguesa é a língua oficial. (MOÇAMBIQUE, 2004, p. 3)

Nesse contexto, pensa-se que as LB moçambicanas foram sendo tratadas de forma discriminada em relação ao Português. A elas, de acordo com a CRM, se atribui o estatuto de patrimônio cultural, como se de pequenos objetos, pequenas relíquias ou obras museológicas se tratasse, como se essas línguas fossem realidades abstratas e isoladas das práticas diárias de seus falantes, quando a prática, sobretudo no contexto africano, mostra que "as línguas não são realidades autônomas, pré-existentes, isoladas e abstratas, mas sim produtos de práticas sociais historicamente situadas" (SEVERO, 2014, p. 11). Isso se nota, por exemplo, pelo fato de apesar de a Língua Portuguesa (LP) ter sido sempre colocada num lugar privilegiado pela minoria e elite governante, a maior parte dos moçambicanos continuou usando majoritariamente as LB, numa clara demonstração de que é através dessas línguas que o povo vive o seu cotidiano, sendo as línguas, de fato, produto de suas práticas sociais.

No artigo 10 da CRM, fica claro que o Português é a língua oficial do país e, secundariamente, no artigo 9, as línguas nacionais (o que se designa, para efeitos desse artigo, por LB moçambicanas) são tidas como patrimônio cultural do país. Essa imposição 
do Português, a língua do ex-colonizador, se arrasta desde o tempo colonial, em que as instituições a serviço do colonialismo português, sobretudo as missões católicas, impunham e priorizavam a LP como língua de ensino e até como meio de diferenciação e de segregação entre os povos colonizados (SEVERO, 2014). Essa situação perpetuou-se durante a luta armada, e até depois da Independência do país, como sustentam Ngunga e Bavo (2011, p. 15), nos seguintes termos:

A questão de uma política linguística que reservava um lugar privilegiado à LP já se adivinhava ainda durante o tempo da luta armada de libertação nacional quando pouco ou nada se discutia sobre o futuro das línguas moçambicanas cuja promoção era considerada nociva à unidade nacional.

Como sugerem esses autores, durante a luta pela independência do país, momento em que se iniciaram no seio da FRELIMO ${ }^{2}$ discussões sobre vários aspectos da futura nação, não foi dada a devida atenção à questão de uma política linguística que abordasse paralelamente e de modo equilibrado o Português e as LB moçambicanas. Prova disso é que finda a luta armada, imediatamente, Moçambique adotou o Português como língua oficial, com o argumento de que essa língua forjaria a unidade nacional e combateria o tribalismo e o regionalismo. Segundo Patel e Cavalcanti (2013, p. 274),

[a] adoção do Português como língua oficial no país remonta a 1962 quando foi criada a Frente de Libertação de Moçambique (FRELIMO) [...] A apropriação da língua do colonizador como oficial foi justificada por uma série de argumentos, sendo talvez o mais forte deles a identificação e diferenciação dos moçambicanos dos outros grupos nacionais na região. Esperava-se que o Português forjasse um novo estado-nação.

Desse modo, não só em Moçambique, mas em vários outros países ex-colônias de Portugal, o Português foi tomado como "símbolo de unidade nacional na construção dos Estados Nacionais africanos a partir dos anos 1970 e convive em situação de multilinguismo com as consideradas línguas nacionais [...]" (SEVERO, 2014, p. 18). Isso ocorre

\footnotetext{
${ }^{2}$ Frente de Libertação de Moçambique, fundada em 25 de junho de 1962 como movimento nacionalista para lutar contra o colonialismo português e pela independência de Moçambique. Após a Independência, em 25 de junho de 1975, a FRELIMO governou o país num regime monopartidário e, depois do Acordo Geral de Paz, com a introdução da democracia multipartidária, transformou-se em partido político, sendo atualmente o partido no poder e a principal força política do país.
} 
em uma situação em que os governos atuais tentam impor o Português como a língua da nação e às vezes como a única língua capaz de representar a nação. Ora, essa imposição serve apenas a interesses políticos, ou seja, contradiz permanentemente o que ocorre na prática, no que se refere ao uso das línguas, pois como postula Severo (2014, p. 11), "línguas não são objetos ou artefatos a serem geridos e impostos sobre as pessoas, mas são produtos das práticas sociais e da vida dialógica dessas mesmas pessoas."

Pelas razões já apontadas, apesar da destacável permeabilidade de uso das LB por parte dos moçambicanos, em Moçambique o ensino foi sendo feito apenas em Português, num país em que, de acordo com Ngunga e Faquir (2011), a grande maioria, cerca de $80 \%$ da população tem, até atualmente, uma LB como língua materna. Como reflexo do "desencontro" entre a língua oficial e de ensino e as línguas usadas de fato pela sociedade moçambicana no seu cotidiano, nas suas vivências e nos aspectos mais importantes de suas vidas, começou a verificar-se na educação recorrentes e altas taxas de reprovação, desistências e, consequentemente, alto desperdício escolar. Acredita-se que isso ocorreu pelo fato de a maioria dos moçambicanos ter passado pela desconfortável e injusta experiência de ser instruída, desde as primeiras classes, em uma língua que, apesar de o Estado instituir como oficial, é na verdade uma língua dominada apenas pela elite minoritária.

Uma grande gama de problemas apresentados para a inclusão das línguas africanas nos sistemas educacionais dos países africanos tem sido discutida. Aqui, o foco é dado apenas a alguns, por exemplo, 1) Contexto africano: O contexto linguístico africano implica, quase sempre, a partilha de espaço entre as línguas nativas e a do ex-colonizador, sendo, muitas vezes, a do ex-colonizador a que predomina na esfera oficial, como é o caso de Moçambique. Isso suscita sempre outros problemas, como 2) Dilemas dos governos africanos na gestão linguística: Que língua escolher? Como o país irá funcionar com mais de uma língua? Essas são perguntas recorrentes e remetem a uma caracterização do multilinguismo como gestor de dificuldades e não como uma diversidade que deve ser cultivada, pois o multilinguismo foi sempre uma característica inerente à África, se se considerar que antes da colonização, os países africanos já eram multilíngues. Esses dilemas levam a maioria dos governos a optar pelo não uso oficial de nenhuma língua africana, em benefício da do ex-colonizador, com a ilusão de que ela é dominada por todos ou que todos a irão aprender e dominar obrigatoriamente. Isso leva a 3) Uma atitude de fechamento das políticas linguísticas envolvendo línguas africanas - em Moçambique: As políticas linguísticas, incluindo as políticas linguísticas para educação, foram veladas durante muito tempo, desencorajando o uso das LB em vários domínios sociais, principalmente 
o oficial (PATEL, 2006; SITOE, 2014). Um dos exemplos que se considera que envergonha Moçambique como um país que se orgulha de ser multicultural/multilíngue é a época em que era literalmente proibido falar as LB nas escolas moçambicanas. Só o Português era permitido!

Alguns anos após a Independência do país, até mais ou menos a década de 1990, era comum ouvir dos professores o seguinte: é proibido falar dialeto ${ }^{3}$ na escola; os alunos eram sujeitos a castigos por falar o dito dialeto. Outro exemplo, conforme Sitoe (2014), foi o grande esforço feito pelo Estado moçambicano um pouco depois da Independência para colocar professores em regiões do país das quais não fossem provenientes, evitando, desse modo, que se comunicassem com os alunos em LB moçambicanas, sendo quase obrigatória a comunicação exclusivamente em Português.

Sitoe aponta algumas razões que teriam justificado tais atitudes em relação às LB moçambicanas, naquela época. Segundo ele, reinava um pensamento segundo o qual:

\begin{abstract}
Não havendo nenhuma língua moçambicana amplamente falada ao nível de todo o país e, consequentemente, não podendo nenhuma delas funcionar ampla e plenamente como uma única língua nacional, só o Português poderia funcionar como língua do Estado, porque etnicamente neutra e por superar parte dos problemas colocados pelas línguas moçambicanas, que incluíam a) o seu estado deficitário por falta de estudos descritivos, ortografias padronizadas, gramáticas, dicionários, etc. b) desconhecimento ou conhecimento insuficiente destas línguas por parte das elites integradas nas instituições do Estado, não as podendo, portanto, usar como línguas de trabalho em atividades oficiais, c) falta de precedentes no uso destas línguas em domínios 'altos'. (SITOE, 2014, p. 43, grifos da autora).
\end{abstract}

Outra questão apontada por Sitoe (2014) como fazendo parte das razões da escolha do Português é o fato de se ter acreditado que essa língua, por ser de comunicação ampla (internacional), facilitaria a integração com outros países. É nesse contexto que se inicia em Moçambique, embora de forma hesitante, um debate sobre a introdução das LB no sistema educacional moçambicano. Diante desse quadro, incluindo pressões feitas por uma parte da academia, sobretudo acadêmicos das universidades Eduardo Mondlane (UEM) e Pedagógica (UP) e da sociedade civil, o governo introduziu oficialmente o EB

\footnotetext{
${ }^{3}$ Durante o tempo colonial, as LB de Moçambique eram denominadas dialetos. Essa designação continuou nos anos pós-Independência e, atualmente, tende a ser cada vez mais contestada e não ser amplamente usada.
} 
a partir de 2002/2003 (PATEL, 2006; CHAMBO, 2013). É importante referir que a introduçao do EB foi antecedida por vários eventos, dos quais se destacam, neste artigo, os que se apresentam na seção seguinte.

\section{0 processo de implementação do EB em Moçambique e seus Antecedentes}

\subsection{Antecedentes}

Como já se mencionou acima, uma das razões que ditou a adoção do Português como língua oficial foi o fato de se acreditar que essa seria a língua de unidade nacional e, por isso, evitaria guerras tribais e rivalidades regionais, numa desesperada tentativa de, como considera Sitoe (2014), matar a tribo para construir a nação. Pois é! Instituído o Português como língua oficial, os problemas não terminaram. Até porque, já durante a luta armada de libertação do país, surgiram no seio da FRELIMO várias crises: movimentos separatistas, divergências políticas, divergências ideológicas e questões sobre o modelo de educação a seguir nas zonas libertadas do colonialismo (MAZULA, 1995). Esse fato nos faz concordar com Patel (2006), que afirma que a constituição da unidade nacional dependia também de outros elementos e não unicamente do fator língua, e que a unidade nacional poderia ser edificada considerando a diversidade étnica, cultural e linguística. E isso não poderia ser visto como impedimento para o desenvolvimento de ações e programas de educação. Apesar de vigorar a LP como a única oficial, pouco depois da Independência, eclodiu uma guerra civil que durou dezesseis anos. Essa guerra desestabilizou o país recém-independente, que se encontrava na fase inicial de sua construção. Um dos setores mais atingidos foi o da Educação, que sofreu um retrocesso sem precedentes na história da jovem nação.

A guerra civil terminou com a assinatura do Acordo Geral de Paz, entre o Governo e a RENAMO ${ }^{4}$, em 1992. O país adotou o sistema de democracia multipartidária e, em 1994, realizaram-se as primeiras eleições gerais. O novo clima de estabilidade permitiu que se repensasse a reconstrução do país (PATEL, 2006). Segundo a mesma autora, o primeiro governo eleito democraticamente, encabeçado pela FRELIMO, partido vencedor das eleições, no quinquênio 1995-1999, estabeleceu desafios/propósitos com vista a

\footnotetext{
${ }^{4}$ Resistência Nacional Moçambicana. Surgiu como um grupo de guerrilha e organizou um movimento armado, que durou dezesseis anos, contra o regime da FRELIMO. É o maior partido político da oposição e o segundo maior do país.
} 
garantir a paz; a redução dos níveis de pobreza; a melhoria da vida do povo etc. No quesito "melhoramento da vida do povo”, destacou-se a Educação no país. O então Ministério da Educação, principal gestor dos programas educacionais, destacou a expansão das escolas primárias, o que implicou a reformulação/transformação imediata do currículo do Ensino Básico (PATEL, 2006). Deve-se salientar que se trata ainda do currículo do Ensino Básico do sistema monolíngue, ou seja, com o Português como única língua de instrução em todo o país.

Para o debate em volta da transformação do currículo, realizou-se o $1^{\circ}$ Fórum de Consulta de Transformação Curricular (1996). Esse encontro foi decisivo para a introdução do EB em Moçambique. Aproveitando-se desse encontro de grande importância, o Instituto Nacional do Desenvolvimento da Educação (INDE) 5 e outros intervenientes que, já desde 1993, vinham desenvolvendo ações visando a introdução das Línguas Bantu no sistema de Educação em Moçambique propuseram a inclusão das LB no novo currículo do Ensino Básico. Pela primeira vez, admitiu-se OFICIALMENTE que as Línguas Bantu fariam parte do ensino formal em Moçambique (PATEL, 2006). Durante o Fórum, o sentimento acolhedor à introdução das LB moçambicanas foi geral, afirma Patel (2006). Segue o extrato de um depoimento do representante do Conselho Cristão de Moçambique, um dos principais representantes da sociedade civil do país, presente no encontro de 1996: "Achamos que é tempo de valorizarmos o nosso Património Cultural. Em particular estamos a falar das Línguas Maternas chamadas Nacionais. Portanto, a Igreja acha que se deveria introduzir o Sistema Bilingue ao nível Primário - Língua Local/Português” (PATEL, 2006, p. 58-59, grifos da autora).

Como se referiu, o INDE já desenvolvia ações em defesa da introdução das LB moçambicanas no ensino. Tais ações se fortaleceram após o Fórum de 1996 (PATEL, 2006). Entre os anos 1993-1997, o INDE desenvolveu atividades de experimentação de uso das LB na educação, em duas províncias: Gaza - Changana/Português; e Tete Nyanja/Português. Com esse arranque, o INDE desenvolve, a partir de 1997, um debate mais contundente sobre a introdução e implementação do EB no Ensino Básico, envolvendo instituições como o próprio Ministério da Educação, confissões religiosas,

\footnotetext{
5 "Instituição subordinada ao Ministro da Educação, com missão de liderar a planificação e o desenvolvimento curricular, realizar investigação de base e aplicada, para o desenvolvimento da educação em Moçambique." (PORTAL DO MINISTÉRIO DA EDUCAÇÃO E DESENVOLVIMENTO HUMANO DE MOÇAMBIQUE, 2016).
} 
universidades (UEM e UP), ONGs e outras organizações da sociedade civil. Como resultado, introduziram-se mais cinco línguas no EB (Emakhuwa, Nyungwe, Sena, Ndau e Rhonga). Na sequência, outras foram sendo incluídas gradualmente, até que em 2003, de acordo com Patel (2006), a distribuição era a que figura no Quadro 1. Para a escolha dessas línguas, foram observados critérios geopolíticos, como cobertura nacional e número de falantes.

Tabela 1. Distribuição das línguas no EB em Moçambique até 2003

\begin{tabular}{|l|l|}
\hline Províncias & Línguas usadas \\
\hline Cabo-Delgado & Emakhuwa, Makonde, Kimwani \\
\hline Niassa & Emakhuwa, Nyanja, Yão \\
\hline Nampula & Emakhuwa \\
\hline Zambézia & Lomwé, Chuwabo \\
\hline Tete & Nyungwe, Nyanja \\
\hline Sofala & Sena, Ndau \\
\hline Manica & Ndau, Tewe \\
\hline Inhambane & Tshwa, Gitonga, Copi \\
\hline Gaza & Changana, Copi \\
\hline Maputo & Rhonga, Changana \\
\hline
\end{tabular}

Fonte: Adaptado de Patel (2006).

Apesar deste sucesso, há que realçar que o processo de introdução do EB em Moçambique não foi e nem é fácil, bem como a sua implementação e manutenção (PATEL, 2006; SITOE, 2014). Na próxima subseção, apresenta-se, à título de exemplo, alguns problemas enfrentados pelas pessoas e entidades que se comprometem com o EB.

\subsection{Alguns problemas}

- Incredibilidade - Reina um clima de incredibilidade por parte da comunidade dominante ou elite falante dominadora do Português, que continua(va) a defender a visão de que o EB dificulta a comunicação, a unidade e a administração do país. 
De acordo com Patel (2006), há uma necessidade de negociação permanente com os gestores da Educação em Moçambique.

- Incapacidade - Os gestores da Educação apresentam frequentemente a justificativa de que os custos para a formação de professores e para a elaboração de materiais $^{6}$ para o EB seriam altíssimos para os cofres do Estado.

- Extremismo - Há o desejo de levar a "guerra" a favor do EB e do uso das LB ao extremo, propondo-se, por exemplo, que se deixe de usar o Português no país, como forma de "ressarcir" os moçambicanos, que durante muito tempo foram obrigados a usar a língua do colonizador. Essa posição tem entrado em choque com a dos que defendem que a LP falada hoje em Moçambique tornou-se também parte da pertença dos moçambicanos e não é mais referência do ex-colonizador, pois os moçambicanos se apropriaram dessa língua e, por isso, deve ser encarada como uma de suas línguas.

O INDE teve, portanto, que encontrar um meio-termo entre as posições antagônicas e mostrar com argumentos fortes a possibilidade de se desenvolver programas de educação bilíngue sem grandes gastos financeiros (PATEL, 2006). Ultrapassdos os problemas mais gritantes, introduziu-se o EB. E dentre os vários modelos disponíveis para o EB, Moçambique teve que optar por um. É sobre esse modelo que passamos a falar na próxima subseção.

\subsection{O modelo transicional}

Com a introdução do EB, Moçambique optou pelo modelo de transição. Sobre esse modelo, Maher (2006, apud PATEL, 2006, p. 67) postula que se baseia em um bilinguismo subtrativo, uma vez que seu objetivo final é subtrair a Língua 1 (L1) do aluno/falante, pois a criança inicia a escolarização monolíngue na L1, passa para um bilinguismo em L1 e Língua 2 (L2) e termina monolíngue na L2.

Sobre o funcionamento do modelo acima referido, conforme Patel (2006, p. 66-67):

\footnotetext{
${ }^{6}$ Atualmente, a elaboração de materiais para o EB decorre de forma sistemática no país. O INDE é o principal órgão que atua na elaboração desses materiais. A Secção de Línguas Bantu da Universidade Eduardo Mondlane tem tido importante participação também.
} 
Primeiro Ciclo ( $1^{\mathrm{a}}$ e $2^{\mathrm{a}}$ classes $)$ A L1 do aluno é o único meio de ensinoaprendizagem; a L1 e o Português são ensinados como disciplina, sendo o Português para desenvolver habilidades de oralidade para preparar a aprendizagem da leitura e escrita nesta língua no $2^{\circ}$ ciclo.

Segundo Ciclo ( $3^{\mathrm{a}}, 4^{\mathrm{a}}$ e $5^{\mathrm{a}}$ classes $)$ Este é o ciclo em que inicia o processo de transição gradual do meio de ensino, de L1 para L2. Assim, no início da $3^{\text {a }}$ classe, os alunos iniciam a aprendizagem da leitura e escrita em Português, através de um processo de transferência de habilidades adquiridas na sua L1. A teoria subjacente a este modelo, conhecida como hipótese sobre interdependência, foi desenvolvida por Cummins (1997), que considera que uma vez que o aluno adquire as habilidades académicas na sua L1 não o fará de novo ao transitar 67 para a aprendizagem na L2, ocorrendo um processo de transferência das habilidades e competências linguísticas já adquiridas.

$[\ldots]$

Terceiro Ciclo (6 e 7a classes) Neste ciclo a língua portuguesa é o único meio de ensino-aprendizagem e espera-se que nesta altura os alunos já possuam um bom desempenho nesta língua, assim como na L1. A L1 será leccionada apenas como disciplina, mas servirá como auxiliar do processo de ensina-aprendizagem, à seme 1 hança do que acontece no $2^{\circ}$ ciclo.

\section{A Figura 2 mostra o processo de transição previsto no modelo:}

Figura 2. O modelo transicional

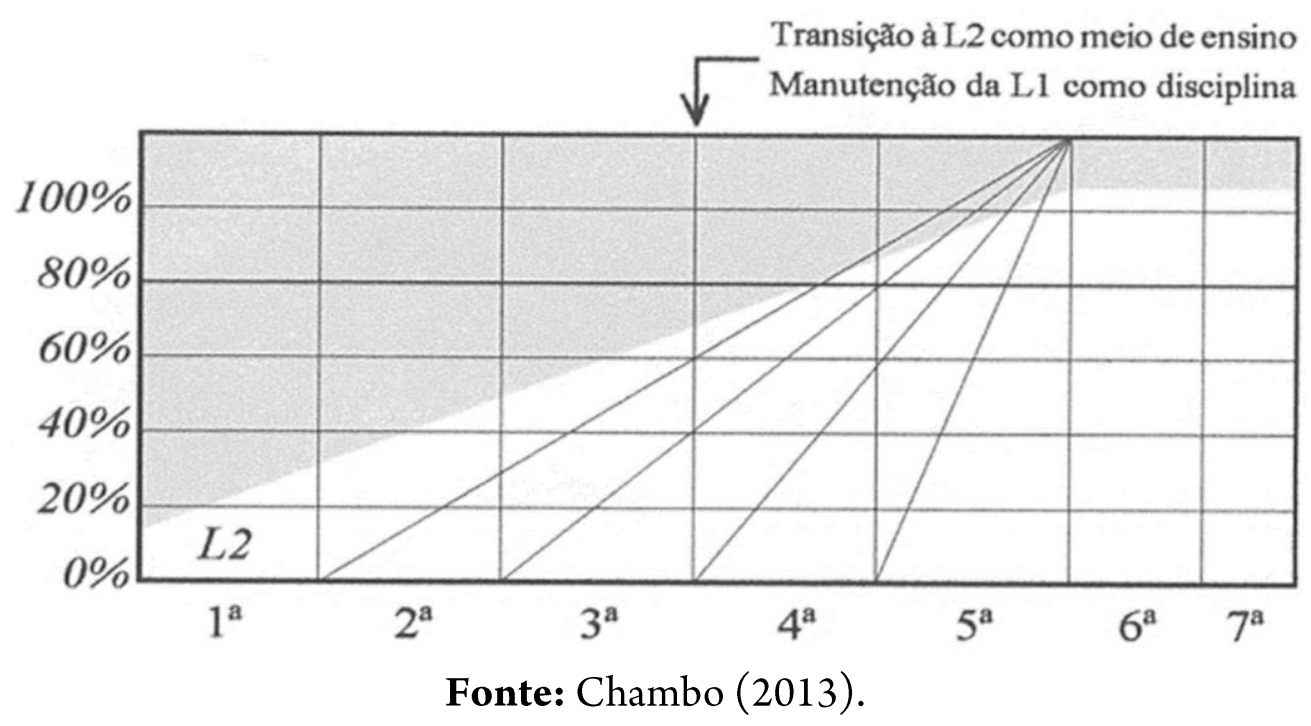


No gráfico, a área sombreada refere-se à L1 e a clareada à L2. Observa-se que o uso da L1, que é massivo nas classes iniciais, vai deixando de ser usado à medida que o aluno caminha para o último ciclo ( $6^{\mathrm{a}}$ e $7^{\mathrm{a}}$ classes). Esse foi o modelo adotado e, como se verificou, apresenta problemas e, consequentemente, reações divergentes entre os sujeitos envolvidos no EB em Moçambique. Na seção que se segue, apresenta-se, de forma representativa, duas posições de dois pesquisadores moçambicanos ligados ao modelo transicional, além de uma avaliação geral do EB e ações em curso com Línguas Bantu.

\section{Ponderações acerca da implementação do EB em Moçambique}

\subsection{Algumas opiniões sobre o modelo transicional}

O sentimento geral é de que esse modelo não é o melhor, pois promove mais a L2 e não a $L 1$, ainda mais em uma situação em que a L2 já leva certa vantagem em termos de anos de existência no sistema de ensino e de prestígio social que a ela se associa.

Gervásio Chambo, docente na UEM e pesquisador em Linguística Aplicada e Políticas Linguísticas, um dos professores com quem conversamos, afirmou que, para ele, o modelo adotado por Moçambique não é o melhor por diversas razões. Algumas são apontadas a seguir:

$\checkmark$ A língua moçambicana não tem privilégio depois da transição, dado que o meio de instrução é desenvolvido em L2;

$\checkmark$ A transição é feita rapidamente, o que cria problemas no sucesso da aprendizagem dos alunos;

$\checkmark$ Esse modelo dá maior enfoque à L2 e não à L1 do aluno;

$\checkmark$ O modelo não promove o bilinguismo aditivo, e sim o subtrativo.

Apesar de se reconhecer que o modelo adotado por Moçambique não é dos melhores, há algum otimismo, considerando que já houve tempos em que nem o EB com base no modelo transicional tínhamos. É assim que pensa Alexandre Timbane, professor na Academia de Ciências Policiais em Moçambique e pesquisador em Políticas Linguísticas, outro professor consultado: 
É o que podemos fazer neste momento. Mesmo a criança não nasce correndo. Precisamos pelo menos dar o primeiro passo. Ainda há problemas de materiais, professores formados, obras literárias etc. O que a África do Sul, Tanzânia e outros países da região têm é fruto de uma política linguística e de planejamento político muito forte. Foram escolhas linguísticas fortes e que hoje colhem frutos, acredito eu. Respeito a opinião dos que atacam o modelo e isso é bom. A ciência é para isso.

Os dois posicionamentos apresentados representam posições antagônicas que permeiam o debate sobre o modelo adotado por Moçambique. Na subseção seguinte, apresentam-se alguns aspectos referentes à avaliação do EB em Moçambique.

\subsection{Avaliação geral do EB}

O relatório de Avaliação da Experiência Piloto de Educação Bilingue do Ministério de Educação em Moçambique (MINISTÉRIO DA EDUCAÇÃO, 2013), apesar de reconhecer que há ainda várias questões por resolver, aponta igualmente aspectos positivos, tais como:

Aumento da taxa de matrículas no EB. Esse relatório indica que, embora as autoridades limitem ainda o EB a uma experiência piloto, o crescimento das taxas de matrícula tem sido resultado da procura do EB por parte das comunidades, fato considerado como o melhor indicador para a relevância desse tipo de educação no país;

Dados sobre desistências obtidos nas escolas e distritos sugerem que a capacidade de retenção do EB (o inverso de desistência e abandono) pode ser melhor que a do sistema monolíngue. $\mathrm{O}$ EB chegou a ter uma retenção de cerca de $88 \%$ a $96 \%$ no período de 2004 a 2010.

Paralelamente à avaliação positiva que se faz sobre o EB, têm ocorrido, em Moçambique, eventos que, de alguma forma, contribuem para fortalecê-lo. A emergência de atividades que visam a promoção, valorização e harmonização das LB mostra que surge, aos poucos, um despertar para uma direção contrária à anterior, em que as LB moçambicanas eram permanentemente corroídas pela LP, sobretudo no domínio oficial 
(NTONDO, 2014). Aos poucos, as LB vão ocupando mais espaço de atuação e ampliando sua circulação até em espaços oficiais. A subseção que se segue se debruça sobre esses eventos, que no presente artigo se designam por "ações encorajadoras”.

\subsection{Algumas ações encorajadoras recentes}

Desde a Independência de Moçambique, a Rádio Moçambique e a Universidade Eduardo Mondlane continuaram desenvolvendo atividades envolvendo LB moçambicanas. A Rádio Moçambique sempre teve emissões radiofônicas e profissionais nas LB (PATEL, 2006). A Universidade Eduardo Mondlane já vinha desenvolvendo tais atividades através do Núcleo de Línguas Moçambicanas (NELIMO), ensinando algumas LB, o que se consolidou com a introdução do curso de Licenciatura em Ensino de Línguas Bantu, em 2005, nessa universidade.

Recentemente, políticos e acadêmicos desenvolveram vários debates que culminaram na introdução e no uso de algumas LB moçambicanas na televisão, no rádio e nas assembleias dos governos provinciais. Pensa-se que essas ações são bastante encorajadoras para a sustentabilidade do EB, bem como para o uso cada vez mais alargado das LB em esferas oficiais do país.

\section{Considerações finais}

De forma geral, reafirma-se que o Ensino Bilíngue em Moçambique trouxe mais inclusão tanto das línguas como dos sujeitos, seus falantes, pois usar as línguas dos indivíduos na sua educação e na educação de seus filhos, e permitir que esses sujeitos usem suas línguas até no meio formal, como na televisão, no rádio etc., são formas de "dar voz" a essas populações. Por isso, acreditamos e propomos que em Moçambique o EB seja encarado como um projeto sério e fundamental para resolver os problemas pedagógicos no sistema de educação (SITOE, 2014) e para a valorização das LB moçambicanas, seus falantes e os eventos sociais cotidianos destes. 
O presente artigo propôs traçar um panorama de uma política linguística baseada numa Política de Intervenção ${ }^{7}$, nos termos descritos por Oliveira (2005), ou seja, uma política linguística em que a população falante participa nas decisões sobre suas línguas, e em que o Estado e a academia colocam-se a serviço das comunidades, partindo da realidade dialógica delas, em vez de as comunidades estarem a serviço do Estado e da academia, como tem estado a suceder. Tal política implica trabalhar em conjunto com as comunidades linguísticas para o desenho de uma política linguística que se adeque ao contexto do país.

\section{Referências}

CHAMBO, G. Pedagogia Intercultural na Educação Bilingue em Moçambique: uma proposta metodológica. Dissertação (Mestrado em Linguística e suas Aplicações) Universidade de Vigo, 2013.

INE. Moçambique projecções 2007 2040. Disponível em:

http://www.ine.gov.mz/estatisticas/estatisticas-demograficas-e-indicadoressociais/projeccoes-da-populacao/mocambique_projeccoes_2007_2040.xls/view. Acesso em: 30 nov. 2016.

MAZULA, B. Educação Cultura e Ideologia em Moçambique: 1975-1985. Maputo: Afrontamentos, 1995.

MINISTÉRIO DA EDUCAÇÃO. Avaliação da Experiência Piloto de Educação Bilingue do Ministério de Educação em Moçambique: relatório de avaliação final, 2013.

MOÇAMBIQUE. Constituição da República de Moçambique, de 16 de novembro de 2004, artigos 09/10, dispõem sobre línguas nacionais e língua oficial. Disponível em: http://www.mozambique.mz/pdf/constituicao. Acesso em: 21 nov. 2016. . Wikipédia, a enciclopédia livre. Flórida: Wikimedia Foundation, 2016.

Disponível em: https://pt.wikipedia.org/w/index.php?title=Mo\%C3\%A7ambique\&oldid=47272435. Acesso em: 21 nov. 2016.

NGUNGA, A.; FAQUIR, O. Padronização da Ortografia de Línguas Moçambicanas: relatório do III seminário. Maputo: Centro dos estudos Africanos, 2011.

\footnotetext{
7 “Política de Intervenção", tal como proposto por Oliveira (2005, p. 1), significa “estabelecer parcerias com as comunidades falantes; escutar essas comunidades, suas demandas culturais e linguísticas, colocando-se a serviço dos seus planos de futuro; qualificar suas demandas a partir de uma relação dialógica, e disponibilizar os meios técnicos a nosso alcance para a consecução dos seus objetivos, ou seja, 'Intervenção' significa então: trabalho conjunto com as comunidades linguísticas que conformam o país.”
} 
NGUNGA, A.; BAVO, N. Práticas Linguísticas em Moçambique: avaliação de vitalidade linguística em seis distritos. Maputo: Centro dos estudos Africanos, 2011.

NTONDO, Z. Línguas Africanas em tempos de mudança. In: Seminário Internacional Acolhendo as Línguas Africanas, 2014. 22 a 26 de setembro.

OLIVEIRA, G. Política Linguística na e para além da Educação Formal. In: Instituto de Investigação e Desenvolvimento em Política Linguística (IPOL), Florianópolis, p. 87-94, 2005.

PATEL, S. Olhares sobre a Educação Bilingue e Seus Professor numa Região de Moçambique. Dissertação (Mestrado em Linguística Aplicada) - Programa de PósGraduação em Linguística Aplicada do Instituto de Estudos da Linguagem, Universidade Estadual de Campinas, 2006.

; CAVALCANTI, M. O Caso do Português em Moçambique: unidade nacional com base em educação bilingue e intercompreensão. In: MOITA LOPES, L. (Org.). O Português no Século XXI: cenário geopolítico e sociolinguístico. São Paulo: Parábola, 2013. p. 274-296.

PORTAL DO MINISTÉRIO DA EDUCAÇÃO E DO DESENVOLVIMENTO HUMANO DE MOÇAMBIQUE. Sobre o INED. Disponível em: http://www.mined.gov.mz/IST/INDE/Pages/estrutura.aspx. Acesso em: 30 nov. 2016.

UNIVERSIDADE EDUARDO MONDLANE. Secção de Línguas Bantu. Línguas Bantu: as nossas línguas. Maputo, 2014. 1 folder.

SEVERO, C. Línguas e Estados Nacionais: problematizações históricas e implicações. In: SERRA, C. (Org.). Estão as Línguas Nacionais em Perigo? Cadernos de Ciências Sociais. Maputo: Escolar Editora, 2014, p. 09-36.

SITOE, B. Línguas Moçambicanas, Como Estamos? In: SERRA, C. (Org.). Estão as Línguas Nacionais em Perigo? Cadernos de Ciências Sociais. Maputo: Escolar Editora, 2014.p. 37-75.

TIMBANE, A. Análise sóciodiscursiva da "saudação" do grupo étnico-linguístico Tsonga de Moçambique. Educação, Cultura e Sociedade, São Paulo, v. 4, n. 2, p. 90-105, jul./dez. 2014.

Data de submissão: 18/07/2016

Data de aceite: 16/08/2016 